\title{
A Study on Change and Difference of Provincial Fishery Efficiency in China
}

\author{
Bo LI* \\ International College of Business and Technology, \\ Tianjin University of Technology, \\ Tianjin, 300384, China \\ Institute of Geographic Sciences and Natural Resources \\ Research, China Academy of Science, \\ Beijing, 100101, China \\ e-mail: mg2011818@126.com \\ Hui-ling QIAO \\ International College of Business and Technology, \\ Tianjin University of Technology, \\ Tianjin, 300384, China
}

\begin{abstract}
This paper uses Chinese provincial panel data, Data Envelopment Analysis (DEA) method, Malmquist index calculation method and Theil index decomposition method to study the efficiency of Chinese fishery and the structure of provincial fishery efficiency differences. The results show that in a large number of Chinese provinces, fisheries are in an inefficient state. In most provinces, fisheries have achieved efficiency gains, which is conducive to the improvement of fishery total factor productivity. The intra-regional differences within eastern, central, western and northeastern China are the major cause of the total provincial efficiency difference in fisheries, while the inter-regional difference is the minor cause. Based on the empirical results, this paper further discusses the relevant political implications.
\end{abstract}

Keywords-Fishery efficiency; Data Envelopment Analysis; Malmquist index; Theil index decomposition.

\section{INTRODUCTION}

Fishery is an integral part of the issues of "Agriculture, Rural areas and Farmers" in China. It is also an important driving force of Chinese national economy. The improvement of fishery efficiency could strongly support the increase of revenue growth and development of fishery. However, there exist apparent regional differences in the allocation of Chinese fishery resources. Under this circumstance, to study the fishery efficiency difference is conducive to providing solutions for improving Chinese fishery economy.

An examination of technical efficiency can provide an understanding of the relationship between inputs and outputs (Duy \& Flaaten 2016). Therefore, in the existing literature, Data Envelopment Analysis (DEA) method was widely used to study the efficiency of fishery production and resource utilization. Especially for Chinese fishery efficiency, previous studies adopted the DEA method (Gao \& Ding, 2011; Li \& Liu, 2014).

\author{
Lin WANG \\ International College of Business and Technology, \\ Tianjin University of Technology, \\ Tianjin, 300384, China
}

However, most of the existing literature paid less attention to the difference of Chinese fishery efficiency. Therefore, this paper measures and analyzes the provincial fishery efficiency and its changing trend using Chinese provincial panel data from 2002 to 2013, DEA method and Malmquist index method. Furthermore, based on the efficiency results, this paper measures provincial difference of fishery efficiency using Theil index, and decomposes the difference to further analyze the contributions of interregional and intra-regional efficiency difference to the total difference using Theil index decomposition method. The political implications of the study results will provide a reference for the coordinated development of Chinese fishery.

\section{METHODS AND DATA}

\section{A. Methods}

The method of DEA was first proposed by Charnes, Cooper and Rhodes (1978), according to which multiple input and output indicators and linear programming were applied to measure the technical efficiency of a production system. Then, in 1994, Fare et al. (1994) proposed the Malmquist index method based on DEA method to measure the total factor productivity change. The method has been widely used in the analysis of technical efficiency and total factor productivity change. Using Malmquist index method, the TFP change of the interested production system could be examined, and the change could be decomposed into technical efficiency change and production technological progress.

In this paper, the above methods are used to study the changing trend of fishery efficiency and the efficiency difference in China. Furthermore, Theil index calculation method is used as an index to measure regional differences, and Theil index decomposition method is used to analyze the structure of difference, which, based on regional groups, could decomposes the total Theil index into intra-regional Theil index and inter-regional Theil indices. 


\section{B. Data}

In this paper, 28 provincial areas including provinces, autonomous regions and municipalities directly under the central government are treated as decision-making units for analysis. The input and output indicators include: (1) input indicators: the provincial total power of motor boats by the end of the year (kilowatts, kw), and fishery population and employees (person); (2) output indicator: total output of fishery products (tons). The data time span is from 2002 to 2013. The data is collected from "Chinese fishery statistical yearbook". The regional division is adopted from "China Statistical Yearbook 2010" $b$.

\section{EFFICIENCY CHANGE AND DIFFERENCE ANALYSIS}

\section{A. Efficiency and Efficiency Change Measurement}

TABLE I. MEASUREMENT RESULT OF CHINESE PROVINCIAL FISHERY EFFICIENCY

\begin{tabular}{|c|c|c|c|c|c|c|c|}
\hline Province & 2002 & $\begin{array}{c}201 \\
3\end{array}$ & Avg & Province & $\begin{array}{c}200 \\
2\end{array}$ & $\begin{array}{c}201 \\
3\end{array}$ & Avg \\
\hline \multirow{2}{*}{ Beijing } & 1.00 & 0.57 & 0.78 & Shandon & 0.83 & 0.6 & 0.74 \\
\hline & 0 & 0 & 6 & $\mathrm{~g}$ & 8 & 34 & 2 \\
\hline \multirow{2}{*}{ Tianjin } & 0.93 & 1.00 & 0.91 & \multirow{2}{*}{ Henan } & 0.53 & 0.6 & 0.45 \\
\hline & 5 & 0 & 3 & & 0 & 73 & 4 \\
\hline \multirow{2}{*}{ Hebei } & 0.72 & 0.50 & 0.58 & \multirow{2}{*}{ Hubei } & 0.69 & 0.6 & 0.63 \\
\hline & 7 & 0 & 0 & & 3 & 17 & 4 \\
\hline \multirow{2}{*}{ Shanxi } & 0.89 & 1.00 & 0.88 & \multirow{2}{*}{ Hunan } & 0.59 & 0.4 & 0.61 \\
\hline & 6 & 0 & 8 & & 5 & 66 & 3 \\
\hline \multirow{2}{*}{ Neimengu } & 1.00 & 0.59 & 0.65 & \multirow{2}{*}{$\begin{array}{c}\text { Guangdo } \\
\text { ng }\end{array}$} & 0.58 & 0.6 & 0.58 \\
\hline & 0 & 9 & 8 & & 7 & 52 & 1 \\
\hline \multirow{2}{*}{ Liaoning } & 1.00 & 0.82 & 0.81 & \multirow{2}{*}{ Guangxi } & 0.56 & 0.4 & 0.51 \\
\hline & 0 & 1 & 0 & & 2 & 61 & 2 \\
\hline \multirow{2}{*}{ Jilin } & 0.55 & 0.31 & 0.48 & \multirow{2}{*}{ Hainan } & 0.56 & 0.7 & 0.61 \\
\hline & 6 & 8 & 9 & & 2 & 03 & 8 \\
\hline \multirow{2}{*}{$\begin{array}{l}\text { Heilongjia } \\
\text { ng }\end{array}$} & 0.42 & 0.44 & 0.42 & \multirow{4}{*}{$\begin{array}{l}\text { Chongqin } \\
\text { g } \\
\text { Sichuan }\end{array}$} & 0.20 & 0.3 & 0.21 \\
\hline & 8 & 2 & 9 & & 7 & 50 & 6 \\
\hline \multirow{2}{*}{ Shanghai } & 0.82 & 1.00 & 0.98 & & 0.84 & 0.7 & 0.58 \\
\hline & 8 & 0 & 4 & & 7 & 36 & 9 \\
\hline \multirow{2}{*}{ Jiangsu } & 0.36 & 0.42 & 0.39 & \multirow{2}{*}{ Guizhou } & 0.17 & 0.1 & 0.16 \\
\hline & 9 & 4 & 5 & & 4 & 23 & 4 \\
\hline \multirow{2}{*}{ Zhejiang } & 0.69 & 0.64 & 0.60 & \multirow{2}{*}{ Yunnan } & 0.41 & 0.9 & 0.51 \\
\hline & 6 & 7 & 8 & & 3 & 44 & 0 \\
\hline \multirow{2}{*}{ Anhui } & 0.52 & 0.39 & 0.45 & \multirow{2}{*}{ Shanxi } & 1.00 & 0.2 & 0.46 \\
\hline & 5 & 5 & 2 & & 0 & 98 & 2 \\
\hline \multirow{2}{*}{ Fujian } & 0.75 & 0.65 & 0.70 & \multirow{2}{*}{ Gansu } & 0.81 & 1.0 & 0.85 \\
\hline & 0 & 8 & 4 & & 9 & 00 & 9 \\
\hline \multirow{2}{*}{ Jiangxi } & 0.61 & 0.35 & 0.53 & \multirow{2}{*}{ Xinjiang } & 0.89 & 0.9 & 0.93 \\
\hline & 0 & 7 & 5 & & 2 & 91 & 0 \\
\hline
\end{tabular}

Using DEA method, the results are shown in Table 1, in which only the efficiencies of 2002, 2013, and average from 2002 to 2013 are listed due to space limitation. As can be seen from the table, there exist obvious provincial differences in the fishery efficiency of the 28 provincial areas. Among them, Shanghai has the highest provincial

\footnotetext{
${ }^{\mathrm{b}}$ The provinces in eastern region include: Beijing, Tianjin, Hebei, Shanghai, Jiangsu, Zhejiang, Fujian, Shandong, Guangdong and Hainan; the provinces in central region includes: Shanxi, Anhui, Jiangxi, Henan, Hubei and Hunan; the provinces in western region include: Inner Mongolia, Guangxi, Chongqing, Sichuan, Guizhou, Yunnan, Shaanxi, Gansu, and Xinjiang; the provinces in northeastern region include: Liaoning, Jilin and Heilongjiang..
}

fishery efficiency, with the average efficiency level of 0.984 . Meanwhile, Guizhou has the lowest provincial fishery efficiency, with the average efficiency level of only 0.164 .

Using Malmquist index method, the changes of efficiency and total factor productivity of Chinese provincial fishery are shown in Table 2 . The technical provincial fishery efficiency increased from 0.851 in 2003 to 0.917 in 2013 with fluctuations. In most years, technical efficiency change and technological change played an active role alternately in promoting the total factor productivity of provincial fishery in China.

\section{B. Measurement and Decomposition of Efficiency Difference}

The regional differences in Chinese fishing efficiencies will definitely hinder the enhancement of the overall efficiency of Chinese fishery. Therefore, it is necessary to accurately measure the inter-regional difference and intraregional differences. In this paper, the four-region-division method is used to divide the provinces into four regional groups including eastern, central, western and northeastern region of China, so as to examine regional differences of fishery efficiency in China.

TABLE II. CALCULATION RESUlTS OF MALMQUIST INDEX

\begin{tabular}{|c|c|c|c|c|c|c|c|}
\hline Year & $\begin{array}{l}\text { EFF } \\
\text { CH }\end{array}$ & $\begin{array}{c}\text { TECH } \\
\text { CH }\end{array}$ & $\begin{array}{l}\text { TFP } \\
\text { CH }\end{array}$ & Year & $\begin{array}{l}\text { EFF } \\
\text { CH }\end{array}$ & $\begin{array}{c}\text { TECH } \\
\mathrm{CH}\end{array}$ & $\begin{array}{l}\text { TFP } \\
\text { CH }\end{array}$ \\
\hline 2003 & $\begin{array}{c}0.85 \\
1\end{array}$ & 1.132 & $\begin{array}{c}0.96 \\
3\end{array}$ & 2009 & $\begin{array}{c}1.06 \\
5\end{array}$ & 0.968 & $\begin{array}{c}1.03 \\
2\end{array}$ \\
\hline 2004 & $\begin{array}{c}1.20 \\
5\end{array}$ & 0.814 & $\begin{array}{c}0.98 \\
1\end{array}$ & 2010 & $\begin{array}{c}1.01 \\
1\end{array}$ & 1.885 & $\begin{array}{c}1.90 \\
6\end{array}$ \\
\hline 2005 & $\begin{array}{c}0.43 \\
9\end{array}$ & 2.322 & 1.02 & 2011 & 0.68 & 1.091 & $\begin{array}{c}0.74 \\
2\end{array}$ \\
\hline 2006 & $\begin{array}{c}2.03 \\
1\end{array}$ & 0.464 & $\begin{array}{c}0.94 \\
2\end{array}$ & 2012 & $\begin{array}{c}1.52 \\
5\end{array}$ & 0.617 & 0.94 \\
\hline 2007 & $\begin{array}{c}1.02 \\
3\end{array}$ & 0.752 & $\begin{array}{c}0.76 \\
9\end{array}$ & 2013 & $\begin{array}{c}0.91 \\
7\end{array}$ & 1.163 & $\begin{array}{c}1.06 \\
6\end{array}$ \\
\hline 2008 & $\begin{array}{c}0.93 \\
7\end{array}$ & 0.981 & $\begin{array}{c}0.91 \\
9\end{array}$ & Avg & $\begin{array}{c}0.99 \\
0\end{array}$ & 1.004 & $\begin{array}{c}0.99 \\
4\end{array}$ \\
\hline
\end{tabular}

Note: (1) EFFCH denotes technical efficiency change; (2) TECHCH denotes technological change; (3) TFPCH denotes total factor productivity change.

In Table 3, the changing trend of Theil index of Chinese provincial Fishery efficiency reflects the variation tendency of regional differences of fishery efficiencies in 28 mainland provinces of China from 2002 to 2013 . From the table, it is clear that the differences of Chinese provincial fishery efficiency fluctuated strongly, which is obviously not conducive to the enhancement of overall fishery efficiency of China.

TABLE III. THEIL INDEX OF CHINESE PROVINCIAL FISHERY EFFICIENCY

\begin{tabular}{cccccccc}
\hline Year & Theil & $\begin{array}{c}\text { Yea } \\
\mathrm{r}\end{array}$ & Theil & Year & Theil & Year & Theil \\
\hline \multirow{2}{*}{2002} & 0.064 & 200 & 0.27 & 2008 & 0.08 & 2011 & 0.174 \\
& 0 & 5 & 90 & & 17 & & 7 \\
2003 & 0.096 & 200 & 0.07 & 2009 & 0.07 & 2012 & 0.062 \\
& 3 & 6 & 78 & & 35 & & 7 \\
2004 & 0.058 & 200 & 0.06 & 2010 & 0.08 & 2013 & 0.080 \\
& 9 & 7 & 82 & & 48 & & 7 \\
\hline
\end{tabular}


Based on the results, Theil index decomposition method is used to quantifiably decompose the difference, so as to find effective ways of reducing regional differences of Chinese provincial fishery efficiency. The decomposition results are shown in Table 4 . As can be seen from the table, the following results are obtained:

(1) Intra-regional difference is the main cause of the overall provincial difference in fishery efficiency of China, while the inter-regional difference is the minor or secondary cause. In 2002, the proportion of intra-regional differences in the overall difference was $97.67 \%$, while the proportion of the inter-regional difference was $2.33 \%$. Despite the subsequent minor fluctuations, the proportions remain generally stable. In 2013, the proportion of intra-regional differences in the overall difference was $96.04 \%$, while the proportion of the inter-regional difference was $3.96 \%$.

(2) The changing trends of intra-regional differences within eastern (E), central (C), western (W) and northeastern (NE) China are different as the time changes. Among them, the proportion of intra-regional difference in western China in the overall difference decreased from $62.15 \%$ in 2002 to $54.74 \%$ in 2013. In most years, it is the highest among regions. The proportion of intra-regional difference in eastern China increased from $18.97 \%$ in 2002 to $56.00 \%$ in 2005. Then it began to decrease to $16.15 \%$ in 2013 with fluctuations. The proportion of intra-regional difference in central China increased from $5.81 \%$ in 2002 to $16.23 \%$ in 2013. In most years, the proportion of intra-regional difference in central China was lower than that in eastern China. The proportion of intra-regional difference in northeastern China decreased from $10.74 \%$ in 2002 to $8.93 \%$ in 2013. Generally, it is the lowest among regions.

TABLE IV. CONTRIBUTION DECOMPOSITION OF THEIL INDEX

\begin{tabular}{|c|c|c|c|c|c|c|}
\hline \multirow{2}{*}{ Year } & \multicolumn{5}{|c|}{ Intra-regional } & \multirow{2}{*}{$\begin{array}{l}\text { Inter- } \\
\text { regional }\end{array}$} \\
\hline & $E$ & $\mathrm{C}$ & W & $\mathrm{NE}$ & Sum & \\
\hline 2002 & $18.97 \%$ & $5.81 \%$ & $62.15 \%$ & $10.74 \%$ & $97.67 \%$ & $2.33 \%$ \\
\hline 2003 & $14.61 \%$ & $13.72 \%$ & $39.71 \%$ & $11.41 \%$ & $79.45 \%$ & $20.55 \%$ \\
\hline 2004 & $19.07 \%$ & $10.84 \%$ & $52.63 \%$ & $7.72 \%$ & $90.26 \%$ & $9.74 \%$ \\
\hline 2005 & $56.00 \%$ & $8.22 \%$ & $20.36 \%$ & $2.28 \%$ & $86.85 \%$ & $13.15 \%$ \\
\hline 2006 & $19.39 \%$ & $18.49 \%$ & $42.23 \%$ & $7.47 \%$ & $87.59 \%$ & $12.41 \%$ \\
\hline 2007 & $20.27 \%$ & $26.42 \%$ & $39.78 \%$ & $6.80 \%$ & $93.27 \%$ & $6.73 \%$ \\
\hline 2008 & $21.85 \%$ & $17.89 \%$ & $51.56 \%$ & $1.40 \%$ & $92.71 \%$ & $7.29 \%$ \\
\hline 2009 & $14.63 \%$ & $19.60 \%$ & $51.82 \%$ & $4.36 \%$ & $90.41 \%$ & $9.59 \%$ \\
\hline 2010 & $10.74 \%$ & $9.53 \%$ & $49.98 \%$ & $6.03 \%$ & $76.28 \%$ & $23.72 \%$ \\
\hline 2011 & $11.59 \%$ & $7.00 \%$ & $54.32 \%$ & $3.34 \%$ & $76.25 \%$ & $23.75 \%$ \\
\hline 2012 & $16.22 \%$ & $12.12 \%$ & $57.67 \%$ & $9.14 \%$ & $95.15 \%$ & $4.85 \%$ \\
\hline 2013 & $16.15 \%$ & $16.23 \%$ & $54.74 \%$ & $8.93 \%$ & $96.04 \%$ & $3.96 \%$ \\
\hline
\end{tabular}

\section{CONCLUSIONS AND POLITICAL IMPLICATIONS}

Based on the empirical results of this paper, the following conclusions and political recommendations could be obtained.
(1) Local government departments should continue to increase investment to strengthen the fishery infrastructure. In addition, policies should be formulated focusing on the promotion of fisheries layout adjustment and the implementation of moratorium system in key fishery areas. Furthermore, it is necessary for local governments in backward provinces to focus on the improvement of fishery efficiency in order to shrink the overall efficiency difference and improve overall fishery total factor productivity. At the same time, the fishery technology promotion and transfer should not be ignored.

(2) Emphasis should be put on the shrinkage of intraregional difference of provincial fishery efficiency. Local government departments in the relatively backward regions should strive to increase fishery scientific research, technology promotion and investment, in order to upgrade the level of fisheries. Furthermore, adequate training and guidance for fishery practitioners should be provided, and effective management and operation system should be implemented in backward provinces to improve the level of fishery development.

(3) The shrinkage of inter-regional difference in provincial fishery efficiency should not be ignored. Relevant government departments should strengthen the regional fishery coordination and activate regional positive interactions through exchange of regional fishery management and operation experience. Furthermore, fishery development strategies should be developed based on local conditions and characteristics, so as to guide the realistic and comprehensive development of Chinese fishery.

\section{ACKNOWLEDGMENT}

This work is supported by grant 16YJCZH040 of Humanities and Social Science Research Foundation Project of China Ministry of Education

\section{REFERENCES}

[1] N. N. Duy, O. Flaaten (2016). Efficiency analysis of fisheries using stock proxies. Fisheries Research, 181, 102-113.

[2] Q. Gao, H. Ding (2011). Measurement of Shandong fisheries production efficiency and trends. Chinese Fisheries Economics, 4, 107-114.

[3] H. Li, W. Liu (2014). Analysis of production efficiency of Marine fishery in Hebei province based Malmquist Index. Jiangsu Agricultural Sciences, 42, 442-444.

[4] A. Charnes, W. W. Cooper, E. Rhodes (1978). Measuring the efficiency of decision making units. European Journal of Operational Research, 2, 429-444.

[5] R. Fare, S. Grosskopf, M. Norris, Z. Zhang, (1994). Productivity Growth, Technical Progress, and Efficiency Change in Industrialized Countries. American Economic Review, 84, 66-83. 